\title{
Biomass furnace for externally fired gas turbine: development and validation of the numerical model
}

\author{
Chiara Galletti $^{\mathrm{a}, *}$, Valentina Giomo ${ }^{\mathrm{a}}$, Simone Giorgetti $^{\mathrm{a}, * *}$, Paolo Leoni $^{\mathrm{b}}$, \\ Leonardo Tognotti ${ }^{\mathrm{a}}$ \\ ${ }^{a}$ Department of Civil and Industrial Engineering University of Pisa, Largo L. Lazzarino 2, \\ 56122 Pisa, Italy \\ ${ }^{b}$ Enel Ingegneria e Ricerca S.p.A, Via Andrea Pisano 120, 56122 Pisa, Italy
}

\begin{abstract}
Externally-fired gas turbines (EFGT) are currently being investigated for cogeneration from biomass, because of their ability to deal with low-grade fuels without the complexity of gasification. Main drawbacks of the technology are related to the high thermal stresses experienced by the heat exchanger. The present work proposes a Computational Fluid Dynamics (CFD) analysis of a grate-fired furnace installed in a EFGT cycle, with the purpose to provide a tool for detecting the most critical regions in the furnace. The model is complemented with a process simulation of the entire EFGT cycle. Different approaches for treating the fuel bed and their impact on the CFD analysis are discussed and validated through the availability of in-flame measurements of temperature and chemical species. Predictions indicate the need for a detailed fluid dynamic characterization of the grate region, which was found to largely impact the furnace flow and thermo-chemical fields.
\end{abstract}

Keywords: micro gas turbine; co-generation; Computational Fluid Dynamics; grate firing

\footnotetext{
${ }^{*}$ Corresponding author

${ }^{* *}$ Corresponding author

Email addresses: chiara.galletti@unipi.it (Chiara Galletti), simone.giorgetti@gmail.com (Simone Giorgetti)
} 


\section{Introduction}

The worldwide concern about global warming and the limited availability of fossil fuels have motivated the use of biomass for energy production. Among the technologies for electricity generation from biomass, small Externally Fired Gas Turbine (EFGT) plants are receiving some attention as they offer the possibility of burning dirty fuels such a biomass in situ, without the complexity of gasification [1] 2. Externally or indirectly fired gas turbine means that hot combustion products do not come in direct contact with the turbine, which operates with a different working fluid; the flue gas thermal power is transferred to the working fluid through a high temperature heat exchanger. Hence, combustion takes place at atmospheric pressure without any need for fuel compression and injection equipments; a wide range of fuels, even solid ones, can be utilized without cleaning systems.

Indeed, the EFGT cycle attempts to combine the advantages of gas turbines (low operational costs, high lifetime and reliability, relatively high energy efficiency even at small size) and the capability of dealing with low quality biofuels.

Recently, many investigations in literature have been aimed at analyzing the EFGT performance and flexibility when burning biomass. For instance, Cocco et al. 3] investigated a small scale EFGT fired with residual biomass to evaluate the influence of pressure ratio, turbine inlet temperature, temperature difference in the heat exchanger and the biomass moisture content on the EFGT performance. Datta et al 4] performed energy and exergy analyses of EFGT cycle integrated with a biomass gasifier, trying to optimize the operating conditions. Pantaleo et al. 5] proposed a thermo-economical analysis of a small scale EFGT fired by natural gas and solid biomass, considering various biomass/natural gas energy input ratios. The maximum investment profitability was obtained for $70 \%$ input biomass percentage. A process and economical analysis was also carried out by Cordiner and Mulone [6] to understand the impact of fuel properties on the performance of a biomass-fired EFGT. More recently Barsali et al- [7] developed a dynamic simulation of a biomass-fired EFGT plant providing 70 
$\mathrm{kW}$ of electricity to be used for control purposes.

Main limitations and problems of EFGT cycles are related to thermal stresses and fouling on the high-temperature heat exchanger [8]. Al-attab and Zainal 9] carried out experimental campaigns aimed at investigating the performance of the high temperature heat exchanger in an EFGT plant. Baina et al. [10] focused the attention on fouling problems of the EFGT high-temperature heat exchanger; their analysis was complemented with a process model of the system aimed at evaluating contaminants coming from biomass combustion [11].

Computational Fluid Dynamics (CFD) could potentially help investigating the furnace behavior, providing the thermo-chemical field and thus giving information useful to detect regions of the heat exchanger with high thermal stresses. In other words, thanks to its ability of supplying local information on temperature and species concentration across the furnace, CFD analysis could enrich the global information obtainable on the basis of the only thermodynamic equilibrium calculations, extensively used in process modeling [12. A detailed experimental investigation is difficult because the usual lack of many accesses to the furnace interior as well as because of the scale of the furnace. Indeed, the need for computational models suited for predicting biomass-fired furnaces, boiler and fluidized bed reactors, is testified by many efforts recently made to upgrade available codes with tools specifically designed to handle the biomass combustion process [13] [14.

In case of biomass, grate-fired furnaces are usually employed because of their larger fuel flexibility, as they can operate with up 100\% raw biomass. However, as a matter of fact, CFD modelling of grate-fired systems is far more complex than of other solid fuel combustion technologies, based on suspended injection systems. The solid biomass bed undergoes a series of non-stationary processes, including drying, pyrolysis and char oxidation. These processes interact with the freeboard, which is characterized by a reactive turbulent flow; things are further complicated by convective and radiative heat transfer. It appears clear that a comprehensive CFD model is difficult, moreover its accuracy would be affected by many assumptions and hypothesis that should be made to model 
the system. Indeed, in literature only a few examples are available on comprehensive models, able to account for the dynamics of the single particle in the biomass bed. Simsek et al. [15] suggested a discrete element code to simulate the reacting moving bed of particles over a grate; the model was then coupled to a CFD simulation of the combustion chamber. Mahmoudi et al. [16] developed the Euler-Lagrange XDEM model, which allows both tracking of the single biomass particles as well as modeling of the gas flow through the void space formed by the particles. Logically, these models are very computationally demanding; so, some efforts have been recently made to speed up simulations of particle-resolved beds either by using representative particles [17] or by modifying the particle sub-model and numerical algorithms [18. However, despite these improvements, only steady calculations are usually carried out; the solid biomass bed is not resolved directly, but an off-line model is developed to provide boundary conditions to the freeboard CFD model [19].

This work is aimed at defining a reliable CFD model of a $550 \mathrm{~kW}$ biomass grate-fired furnace in a EFGT system providing about $70 \mathrm{~kW}$ of electricity; the model is expected to represent a useful tool to detect critical regions, as high temperature zones in the heat exchanger. The furnace is related to the EFGT cycle through a process model which is developed in order to set proper boundary conditions to the CFD model. In-flame measurements of temperature and chemical species are used to validate and choose the numerical approach.

\section{EFGT plant}

\subsection{EFGT cycle}

The investigated EFGT plant (see Figure 1) belongs to ENEL and it is sited in Livorno. The T100 Turbec (ABB/Volvo) turbine was modified on purpose, by replacing the original combustion chamber with an external furnace ; here highpressure air flows within a tube bundle placed in the furnace, so that it is heated before entering the turbine for expansion. The discharged air is partly utilized for biomass oxidation and partly to dilute the flue gases. Combined heat and 
power has been considered by including a high temperature heat exchanger for co-generation [20]; furthermore, the plant comprises a flue-gas cleaning system, consisting on a cyclone that separates the particulate matter.

[Figure 1 about here.]

\subsection{Furnace}

The furnace, which is approximately $4.5 \mathrm{~m}$ long, is depicted in Figure 2, and it shows an unconventional design; the heat exchanger is basically a tube bundle composed of 56 staggered pipes grouped in two rows. The grate is located at the bottom of the combustion chamber and it has two main functions: lengthwise transport of the fuel from the inlet on the front wall to the ash discharging system on the opposite wall and distribution of the combustion air. The air required for devolatilization and oxidation is fed into the grate through nozzles located underneath the grate (primary air) and through squared nozzles in the grate walls (post-combustion air). The furnace burns approximately $185 \mathrm{~kg} / \mathrm{h}$ of biomass and operates at an overall air-fuel equivalence ratio of about 1.3, corresponding to an oxygen concentration in the stack of $12 \mathrm{vol} \%$. The flue gases thermal power is partially absorbed by the air inside the tube bundle and

partially used for co-generation. A small aliquot of the energy, about $10 \%$ of the combustion power, is lost by conduction to the walls of the boiler.

[Figure 2 about here.]

\subsection{Experimental campaigns}

Experimental campaigns were carried out using four different biomass fuels (wood chips, urban green waste, olive kernel and giant cane), showing a large plant flexibility with respect to the biomass characteristics. In this paper only the campaign performed with wood chips is considered [21. Process parameters, species concentration and temperature of the flue gas and combustion air were collected; these parameters are reported in Table 1 along with the biomass proximate and ultimate analyses. The temperature of the air entering 
the turbine was kept lower than the nominal temperature Turbec GT, to avoid problems related to the material of the high temperature heat exchanger [21]. Furthermore, in-flame measurements of temperature and species $\left(\mathrm{CO}_{2}, \mathrm{CO}\right.$, $\mathrm{O}_{2}, \mathrm{NO}$ and $\mathrm{SO}_{2}$ ) concentrations were carried out at the locations shown in Figure 2 along the axial (lengthwise to the grate) and transversal (perpendicular to the grate) directions in the furnace. The IFRF suction pyrometer was used to measure temperature, whereas a suction probe connected with a FTIR (Fourier Transform InfraRed) spectrometer was employed to measure the gas composition.

[Table 1 about here.]

\section{Process model}

Some quantities necessary for setting the furnace CFD model are not directly ready from the experimental campaign, but need to be derived from the available measurements. Combustion air and flue gas mass flow rates as well as thermal losses of the boiler are unknown, but they are essential for defining the furnace CFD model. Hence, the entire process of the power plant was analyzed using the Aspen Plus ${ }^{\circledR}$ software as illustrated in Figure 3.

The process scheme can be divided in two parts: the power plant (including the turbine, the compressor, the electric generator, the heat regenerator, the electric engine and the mixer) and the furnace, where each phase of the biomass combustion is considered. These two parts interact by the heat exchanger (BEAM), that represents the tube bundle, and by the mass flow rate of air exiting from the turbine and entering the boiler. The results given by the process simulator are summarized in Table 2 ,

[Table 2 about here.]

[Figure 3 about here.] 


\section{CFD model}

\subsection{Methodology}

Modeling biomass combustion in a grate-fired furnace can be decomposed into two sub-problems: modeling the biomass bed and simulating the gas-phase reactions in the freeboard. The biomass bed model plays a key role because it provides the inlet conditions for the freeboard simulations. In literature, iterative methods are suggested between the in-bed fuel conversion model and the freeboard CFD simulation, until there is no substantial difference in either the combustion gas leaving the fuel bed or the radiative heat flux incident onto the fuel bed 22.

However the furnace investigated in the present work shows some peculiar features in comparison with traditional grate-fired furnaces; in particular the grate is placed in a limited region and it is located much below the heat exchanger region. The grate extends horizontally for approximately $40 \%$ of the furnace base section, whereas in conventional furnaces the grate occupies almost all the base section. Therefore the radiative contribution is expected to be less important than in standard vertical boilers. For that reason, the modeling was simplified by decoupling radiation of biomass bed and freeboard. This was made by setting the bed absorption factor equal to zero; in this way the incident radiation

to the inlet is entirely reflected and the energy balance is respected without any need for an iterative method.

\subsection{Biomass bed model}

The in-bed fuel model aims at deriving the profiles of temperature, composition and velocity of the gas leaving the fuel bed into the freeboard, based on feeding rate and composition of the wood chips as well as of inlet air. For the biomass bed, an off-line model is applied, considering only the final products released from the evaporation, pyrolysis and char combustion. Volatiles are lumped into one single species, $C_{1.06} H_{2.24} O_{0.92} N_{0.0028} S_{0.0002}$, whose formula and enthalpy of formation are determined from the biomass analysis. Char in 
the fuel bed is assumed to be completely oxidized into $\mathrm{CO}$ and $\mathrm{CO}_{2}$; however the concentration of $C O$ is negligible, because of the low temperature of the fuel. Indeed the $\mathrm{CO}$ to $\mathrm{CO}_{2}$ ratio can be calculated for temperatures between 730 and $1170 \mathrm{~K}$ as 23] 24]:

$$
\frac{C O}{C O_{2}}=2500 \cdot \exp -\frac{6420}{T} .
$$

Hence, five species (i.e. $\mathrm{H}_{2} \mathrm{O}$, volatiles $\mathrm{C}_{1.06} \mathrm{H}_{2.24} \mathrm{O}_{0.92} \mathrm{~N}_{0.0028} \mathrm{~S}_{0.0002}, \mathrm{CO}_{2}, \mathrm{O}_{2}$ and $N_{2}$ ) are considered in the gas released from the biomass bed.

Three different approaches for treating the biomass bed were applied:

- model \#1 - uniform release of temperature and chemical species;

- model \#2 - release of temperature and chemical species dependent on the lengthwise position on the grate (zonal release);

- model \#3 - detailed fluid dynamic model of the grate region, in which the steps of the grate and the air feeding are included (CFD bed model).

All the approaches are represented in Figure 4 The first and second methods are commonly used and justified in literature, where it is reported that the freeboard is influenced by the in-bed conversion model only in the vicinity of the fuel bed [25]. So, a common procedure is to treat the biomass bed as an inlet region with a release of flue gases, coming from the biomass combustion. Practically, the biomass bed is substituted by a surface which is treated as an inlet section in the freeboard CFD model. In other words, the steps of the grate are not considered in order to simplify the problem; thus the products of biomass bed vaporization, devolatilization and char oxidation are released from a virtual surface above the biomass bed (see Figure 44. In each model the released gas species are the same, but their distribution is different [25]. In the first model a homogeneous mixture of chemical species is assigned to the inlet of the freeboard. The velocity is uniform and perpendicular to the inlet. The gases have also a homogeneous temperature, which is calculated by an energy balance. In the second approach, the freeboard inlet is divided lengthwise into four sections, and for each section, 
material and energy balances are applied to determine the mixture composition, flow rate and temperature. Practically each of the four regions is treated as a perfectly stirred reactor $([26])$. The biomass conversion rate is prescribed for each reactor, hence as a function of the position on the grate on the basis of the experience, as suggested by [25] and shown in the upper part of Table 3 for sake of clarity. Finally, the third model incorporates also injection air nozzles, whereas water vapor, volatiles and carbon dioxide are still considered as a homogeneous mixture, released by the base of the grate steps. The model suffers from uncertainties associated with the air flow distribution among the air injection nozzles, which is not available from experimental measurements. An attempt was made to measure the repartition between primary and postcombustion air, but the absence of a piece of straight pipe long enough to allow the streamlines to develop, limits strongly the reliability of measured flow rates. Moreover, even though the amount of total air could be measured, it is difficult to know the exact rate flowing through each injection nozzle. Hence it was assumed that the flow rate is uniformly distributed among the individual nozzles corresponding to primary and post-combustion air.

[Figure 4 about here.]

[Table 3 about here.]

\subsection{Freeboard model}

The CFD model of the freeboard is, basically, a gas-phase turbulent combustion model. The complex geometry requires an unstructured grid which was made with the Ansys ICEM software. The unusual disposition and the small distance between the pipes forced a high-density mesh near them. A grid independence study was performed using non-reacting simulations and varying the number of tetrahedral cells from $1.85 \mathrm{M}$ to $4.3 \mathrm{M}$; then, the optimal grid was converted to a polyhedral grid constituted by $0.85 \mathrm{M}$ cells, with a minimum orthogonal quality of 0.396 . The use of polyhedrons improves convergence and accuracy as the number of near neighbors is higher than those of tetrahedrons. 
The grate region considered in model \#3, was discretized through a structured grid made by $1.8 \mathrm{M}$ hexahedral cells, that was combined to the polyhedral grid needed for the freeboard, leading to a total number of elements of about $2.65 \mathrm{M}$ cells. The circular air injection nozzles were replaced bnozzlesy square with equivalent sections in order to facilitate the creation of a structured grid in the grate region. Primary and post-combustion nozzles are depicted in Figure 4. Simulations are based on Favre-averaged Navier-Stokes equations.

$$
\begin{gathered}
\nabla \cdot(\bar{\rho} \tilde{\mathbf{v}})=0 \\
\nabla \cdot(\bar{\rho} \tilde{\mathbf{v}} \tilde{\mathbf{v}})=-\nabla \tilde{p}-\nabla \cdot \tilde{\tau}-\nabla \cdot(\bar{\rho} \widetilde{\mathbf{v}} \overline{\mathbf{v}} ")+\bar{\rho} \mathbf{g}
\end{gathered}
$$

where the $\tilde{\phi}$ represents the Favre-average of the $\phi$ variable, i.e. $\tilde{\phi}=\frac{\overline{\rho \phi}}{\bar{\rho}}$. The Reynolds stress tensor $-\bar{\rho} \mathbf{v}$ "v" is closed through the eddy viscosity assumption as

$$
-\bar{\rho} \mathbf{\mathbf { v }} \mathbf{v} "=-\bar{\rho} \nu_{t}\left[2 \mathbf{S}-\frac{2}{3} \nabla \cdot \tilde{\mathbf{v}} \mathbf{I}\right]+\frac{2}{3} \bar{\rho} \tilde{\kappa} \mathbf{I}
$$

where $I$ is the unit tensor. The eddy viscosity $\nu_{t}$ is calculated from the Favreaveraged turbulent kinetic energy $\tilde{\kappa}$ and its dissipation $\tilde{\varepsilon}$ according to the standard $\kappa-\varepsilon$ model [27], as:

$$
\nu_{t}=c_{\mu} \frac{\tilde{\kappa}^{2}}{\tilde{\varepsilon}}
$$

where $c_{\mu}=0.09$. Model equations are solved for $\tilde{\kappa}$ and its dissipation $\tilde{\varepsilon}[27]$. The effect of the turbulence model is considered by using also the realizable $\kappa-\varepsilon$ [28] and standard $\kappa-\omega[29$ ] turbulence models when performing simulations for model \#3. The Favre-averaged equations for reactive scalars $\psi_{i}=$ $\left(Y_{1}, Y_{2}, . ., Y_{N}, T\right)^{T}$, where $Y_{i}$ is the mass fraction of the i-th chemical species, are:

$$
\bar{\rho} \bar{v} \cdot \nabla \tilde{\psi}_{i}=\nabla \cdot\left(\overline{\rho D_{i} \nabla \psi_{i}}\right)-\nabla \cdot\left(\bar{\rho} \widetilde{v^{\prime \prime} \psi_{i}^{\prime \prime}}\right)+\rho \tilde{S}_{i}
$$

$D_{i}$ represents the mass or the thermal diffusivity, whereas $S_{i}$ the chemical or the temperature source term (the latter including both chemical reaction as well as radiative heat sources). The turbulent transports $-\nabla \cdot\left(\bar{\rho} \widetilde{v^{\prime \prime} \psi_{i}^{\prime \prime}}\right)$ are modeled through the gradient hypothesis, whereas the chemical source terms are resolved by treating the turbulence/chemistry interaction through the Eddy Dissipation 
Model (EDM). Accordingly, the reaction rates are assumed to be controlled by the turbulent mixing [30]:

$$
\bar{\rho} \tilde{S_{F}}=\min \left(\bar{\rho} \frac{\tilde{\varepsilon}}{\tilde{\kappa}} \tilde{Y}_{F}, A \bar{\rho} \frac{\tilde{\varepsilon}}{\tilde{\kappa}} \tilde{Y}_{O}, A B \bar{\rho} \frac{\tilde{\varepsilon}}{\tilde{\kappa}} \tilde{Y}_{P}\right)
$$

$\tilde{Y}_{F}, \tilde{Y_{O}}$ and $\tilde{Y}_{P}$ represent the fuel, oxidizer and product mass fractions, respectively. The fuel combustion rate is in $\mathrm{kg} /\left(\mathrm{m}^{3} \cdot \mathrm{s}\right)$, with $A$ and $B$ constants of 4 and 0.5. EDM is largely used for combustion process, as oxidation reactions are usually much faster than the turbulent mixing scales. The model is computationally cheap and requires only one or two-step reaction mechanisms; hence volatiles oxidation was described as:

$$
\begin{aligned}
\mathrm{C}_{1.06} \mathrm{H}_{2.24} \mathrm{O}_{0.92} \mathrm{~N}_{0.0028} \mathrm{~S}_{0.0002}+0.63 \mathrm{O}_{2} \rightarrow & 1.06 \mathrm{CO}+1.12 \mathrm{H}_{2} \mathrm{O} \\
& +0.0014 \mathrm{~N}_{2}++0.0002 \mathrm{SO}_{2} \\
\mathrm{CO}+0.5 \mathrm{O}_{2} \rightarrow & \mathrm{CO}_{2}
\end{aligned}
$$

Negative homogeneous heat fluxes of $6.38 \mathrm{~kW} / \mathrm{m}^{2}$ and $3.62 \mathrm{~kW} / \mathrm{m}^{2}$ were applied to the heat exchanger pipes and to the furnace walls, respectively. Such values were derived from the process simulation described in Section 3.

The P-1 model, based on the expansion of the radiation intensity into an orthogonal series of spherical harmonics, is used for radiative heat transfer. A constant emissivity of 0.7 was used for the pipes, whereas the radiative properties of the gas were evaluated through the Weighted-Sum of Grey Gas model with coefficient from Smith 31. In this study, soot or fly ash content particles are not included in the freeboard CFD simulation: very low ash content in the wood chips justifies this.

The finite volume solver ANSYS Fluent v.14.5 was used to perform these simulations. All equations were calculated using a steady state solver and a second order upwind discretization; the SIMPLE algorithm was employed for pressure and velocity coupling. Residuals had a slow convergence: they reached their stability at $10^{-5}$ except for the continuity equation, which it reaches the stability at $10^{-4}$. The overall energy balance was also check to assess convergence of 
simulations.

\section{Results}

\subsection{Models \#1 and \#2}

Figures $5 \mathrm{a}$ and $5 \mathrm{~b}$ compare measured temperatures with predicted values along the axial and transversal directions, respectively for each model. The axial profile of temperature estimated by the uniform release model (model \#1

) is much different from the measured one. In particular predictions show a temperature peak where measurements indicate a flat region and conversely a flat temperature profile where experiments suggest a temperature peak. An improvement of the temperature prediction may be achieved by adopting nonuniform inlet conditions (model \#2). However, the use of experience-based repartition of the biomass combustion processes (evaporation, devolatilization, char oxidation) between the different regions of the bed, as reported in the upper section of Table 3 leads to a unsatisfactory prediction of the axial profile of temperature, as indicated by the zonal model in Figures 5a. Much better fitting of the axial profile of temperature can be obtained by setting different conversion rate of the biomass combustion processes and using data in the lower section of Table 3 (see zonal model - opt. in Figure 5

As a matter of fact, the experience-based conversion distribution suggested in literature has been obtained in grate-fired systems much different from the present one, especially because the different injection of air. Thus it was decided to vary the conversion values in order to roughly capture the axial profile of temperature. This profile was chosen because it is measured just above the bed. Logically the procedure is iterative, with continuous adjustments of the conversion rates, according to the predicted thermal and flow fields. The lower part of Table 3 reports the rates obtained at the end of the procedure; it can be noticed that the devolatilization process now extends up to the third region.

[Figure 5 about here.] 
However, the transversal profile of temperature predicted by model \#2 shows large discrepancies with respect to the experimental data (see Figure 5b), even when using optimized conversion rates. Moreover, the axial profile of $\mathrm{CO}_{2}$ shown in Figure 6a, indicates a large underestimation of the measured values by both models $\# 1$ and $\# 2$. This may suggest that the reaction region should be located closer to the inlet than that predicted by the models. In other words, experiments indicate an high concentration of combustion products (and low concentration of the oxidant) at the location where axial measurements have been taken, whereas, according to predictions, volatiles oxidation has not occurred yet.

[Figure 6 about here.]

Indeed both models \#1 and \#2 show that combustion takes place very close to the pipes of the heat exchanger; hence many of them are subjected to high temperatures. Figure 7 shows pathlines and temperature distribution in the furnace as predicted by model \#2 with optimal conversion rates. Results from model \#1 are not shown but they are very similar in predicting the high temperature region near the pipes of the heat exchanger. This is because, according to EDM, combustion rates are proportional to turbulent mixing, and thus to the ratio between the turbulent dissipation rate and the turbulent kinetic energy, i.e. $\frac{\tilde{\epsilon}}{\tilde{\kappa}}$, see Equation 7. The large release section leads to low turbulent mixing rate values near the inlet, so that the high mixing region is the one close to the pipes, where subsequently combustion takes place.

[Figure 7 about here.]

In literature there are some attempts to modify the EDM constants in order to improve predictions for biomass grate-fired systems. For example Yin et al. [32] suggested to vary the $A$ and $B$ constants of the EDM model (see Equation 7) to reduce the temperature peaks, obtaining an optimal value of $A=0.4$ (instead of $A=4$ ). As a matter of fact the use of modified value of $A$ and $B$ 
constants for biomass/coal has been also applied in other works in literature (see for example [33]). However, in the grate-fired furnace investigated in the present work, the inlet section is too large to get high mixing rates closer to the inlet; consequently combustion occurs near the pipes where higher turbulent mixing rates are evaluated. The change of $A$ and $B$ constants of the EDM model is ineffective. In addition, also the transversal profile of temperature (see Figure 5 b) indicates a peak of temperature that cannot be predicted by imposing a release of combustion products from the inlet in the vertical direction.

\subsection{Model \#3}

The observation made in previous Section 5.1 motivated the development of a complete model (model \#3) including the grate region and the air injection nozzles. The resulting flow and temperature field in the furnace are shown in Figure 8. It is evident from Figure $8 \mathrm{~b}$ that the release from the surface which represents the inlet section for models \#1 and \#2, is far from being uniform, with the presence of a high velocity region near the last steps of the grate. It can be even noticed the presence of a reverse flow near the first steps of the grate due to recirculation promoted by the momentum carried by the jets of the primary air. According to model \#3, the pipes of the heat exchanger which are subjected to higher temperature are just those above the latter steps of the grate.

[Figure 8 about here.]

Figure $5 \mathrm{a}$ and $5 \mathrm{~b}$ indicate that model \#3 better captures both axial and transversal profile of temperature. In particular the model is the only one capable of capturing the trend and the peak of the transversal profiles of temperature. This highlights the importance of considering the distribution of the inlet air and its influence on the fluid dynamics of the bed for the present furnace. Such improvement is noticeable despite the uncertainties on the air distribution mentioned at the end of Section 4.2 .

The axial and transversal profiles of the main chemical species (see Figure 6) 
indicate a better performance of model \#3 than models \#1 and \#2; however there are discrepancies, which suggest further improvements of the model.

The predictive performance of the models was evaluated through averaged relative and absolute errors. The average absolute error $E_{a}$ can be calculated as:

$$
E_{a}=\frac{1}{N} \cdot \sum_{1}^{N}\left|\psi_{e}-\psi_{p}\right|
$$

wheres the average relative error $E_{r}$ as:

$$
E_{r}=\frac{1}{N} \cdot \sum_{1}^{N} \frac{\left|\psi_{e}-\psi_{p}\right|}{\psi_{e}}
$$

$N$ represents the number of observations, whereas $\psi_{e}$ and $\psi_{p}$ are, respectively, the values of the experimental and predicted variable (for instance averages of temperature or mass fractions). Relative errors will be used for temperature, whereas absolute ones will be used for mass fractions, as the calculation of relative errors may diverge because mass fractions can be zero in some locations. Table 4 reports the errors provided by each model, confirming the better performance of model \#3 than models \#1 and \#2 for both temperature and chemical species.

[Table 4 about here.]

The effect of the turbulence model on predictions provided by model \#3 was investigated by comparing the standard $\kappa-\varepsilon$ model with the realizable $\kappa-\varepsilon$ and the standard $\kappa-\omega$ models. Temperature profiles are shown in Figure 9 and indicate a slightly better performance of the standard $\kappa-\varepsilon$ model.

The standard $\kappa-\varepsilon$ model was found to provide average relative errors on the axial temperatures of $8.7 \%$ whereas the realizable $\kappa-\varepsilon$ and the standard $\kappa-\omega$ models of $12.6 \%$ and $12.9 \%$, respectively. The errors for the transversal profile of temperature were of $6.4 \%, 10.6 \%$ and $9.9 \%$ for the standard $\kappa-\varepsilon$, realizable $\kappa-\varepsilon$ and the standard $\kappa-\omega$ models, respectively.

[Figure 9 about here.] 
Predictions of the $\mathrm{CO}_{2}$ also indicated a slightly better performance of the $\kappa-\epsilon$ model, especially along the transversal direction.

\subsection{Preliminary model \#4}

The previous section clearly shows that, for the particular furnace investigated, the grate region cannot be treated as an inlet surface releasing biomass combustion products in the vertical direction, but that the fluid dynamics, as forced by the air injection nozzles, should be considered. However model \#3 treats the grate region as a fluid zone, that means pressure drops provided by the layer of biomass bed above the grate are not considered. The biomass/char bed improves diffusion of the inlet air jets, thus decreasing their momentum. Consequently the temperature field and the distribution of chemical species in the entire furnace could be very influenced.

For this reason, an attempt was made to develop a semi-porous model (model \#4) by treating the biomass bed above the steps of the grate as a porous media. This model will be regarded as a preliminary investigation as there are many uncertainties in its setting up that demand for more detailed experimental campaigns in future.

The height of the porous region was roughly evaluated by assuming the load of biomass, a density of the wood chips of $300-350 \mathrm{~kg} / \mathrm{m}^{3}$ as given by the biomass supplier and a void fraction of 0.51 , which was derived from the ratio between this density and the density of wood $\left(620 \mathrm{~kg} / \mathrm{m}^{3}\right)$. The grate region is depicted in Figure 10 along with indication of the porous zone.

[Figure 10 about here.]

The porous region is aimed at analyzing the effect of the obstruction of the biomass to the air flow, so a non-reactive porous bed model is considered. A source of pressure drops is applied to the porous region and was evaluated through the Ergun's equation as:

$$
\frac{|\Delta p|}{l}=\frac{150 \mu}{D_{p}^{2}} \frac{(1-\epsilon)^{2}}{\epsilon^{3}} v_{\infty}+\frac{1.75 \rho}{D_{p}} \frac{1-\epsilon}{\epsilon^{3}} v_{\infty}^{2}
$$


where $l$ is the height of the biomass bed, $\rho$ and $\mu$ are the fluid density and viscosity, respectively, $d_{p}$ is the equivalent diameter of the particles that form the biomass bed, $\epsilon$ is the porosity of the bed and $v_{\infty}$ is the undisturbed air velocity. The equivalent diameter of the particles is difficult to be evaluated as only the dimensional class of the wood chips is known, but no information is available on the shape and dimensional distribution. Moreover one should consider that biomass undergoes combustion so both size and shape changes in the bed. For these reasons, the porous model was implemented using different equivalent diameters $d_{p}$ as shown in Table 5. The porosity of the bed $\epsilon$ was kept equal to 0.51 for all cases.

[Table 5 about here.]

Figures 11a, 11b and 11; show the pathlines of the single-phase model, the $1^{\text {st }}$ porous bed model and the $3^{\text {rd }}$ porous bed model respectively. The $2^{\text {nd }}$ porous model is not represented because its results are similar to those of the $3^{\text {rd }}$ porous model. It is evident that the obstacle provided by the biomass gives an important contribution to the fluid dynamic of the entire furnace. The magnitude of the velocity vectors decreases significantly and the jets are less strong with respect to the single-phase model (model \#3).

[Figure 11 about here.]

The above evidence suggests a more detailed characterization of the biomass bed in order to get reliable input data for the porous media. For the $2^{\text {nd }}$ equivalent diameter, the resulting errors on temperature and $\mathrm{CO}_{2}$ are reported in Table 4 and show absolutely no improvement with respect to model \#3. In particular errors on temperature were larger than those predicted by model \#3 along both the axial and transversal directions. However the effect of a layer of particles on the primary air suggests a further improvement on the porous model, based on more data from the experimental campaigns. 


\section{Conclusions}

In the present work, a grate-fired furnace in a EFGT cycle was modelled through CFD with the aim to provide a tool for estimating the pipes of the heat exchanger which are subjected to higher thermal stresses. A process model of the EFGT cycle was also developed in order to provide inputs to the furnace CFD model. Different approaches for treating the biomass bed were compared, highlighting the need to take into account the fluid dynamics imposed by the injection of primary and post-combustion air.

Basically, the biomass bed could not be handled as a surface releasing flue gases, but a detailed fluid dynamic characterization of the grate region was required. All these considerations were possible only because of the availability of in-flame temperature and chemical species data, which were used to validate the different approaches. In particular, representing the grate region as just an inlet surface with either uniform of length-wise dependent release of flue gases, leaded to low turbulent mixing above the bed. Reactions were therefore found to take place near the heat exchanger pipes, characterized by higher mixing, so that almost all the pipes were subjected to high temperatures.

Despite the lack of knowledge of the feeding air distribution through the specific primary and post-combustion nozzles, the adoption of a model which takes into account the fluid dynamic in the grate region was found to largely improve the predictions.

A further advancement in the model could be pursued by defining a porous layer above the grate of the furnace, to emulate the resistance given by the biomass/char bed to the injection air jets. To do that, detailed knowledge on the biomass/char dimensional distribution is desirable. Similar issue was recently raised by Shiehnejadhesar et al. 34] who proposed a streak model to take into account the porous biomass region of a grate-fired furnace.

All the above considerations clearly indicate that predicting grate-fired furnaces needs many efforts from both modeling and experimental perspectives. Advanced monitoring and testing are needed to provide reliable and complete 
inputs to the model, as also highlighted by Yin et al. 22. Importantly, the availability of in-flame measurements could guide and suggest the adoption of new models for the biomass grate-fired systems.

Logically, a further improvement could be gained also by considering all sources of uncertainty that may affect the measured data, including those needed as model inputs [19] [35]. For instance, the use of different turbulence models was found to lead to predictions that differ from each other less than about $60 \mathrm{~K}$ at most of the locations. An analysis of errors associated with the temperature measurement by means of the IFRF suction pyrometer was not specifically carried out, but the errors evaluated for the same instrument in a semi-industrial scale furnace are reported to be of about $5 \%$ of the measured values [36], that means 50-60 K; hence the same magnitude of the numerical uncertainty due to the choice of the turbulence model. A more robust and reliable bed model is yet to be developed, for example, by considering the transient features of the biomass feeding as well as instabilities in the fuel bed [32. Moreover, the CFD modeling needs to be extended to other topics of interest (e.g. NOx and soot emissions) once the fundamental knowledge is gained. These latter topics may demand an improvement of the kinetics as well as of the turbulence/chemistry interaction model used in the present study 37 .

\section{Acknowledgements}

The research was carried out within the "BioPower in Tuscany" project,

funded by the Tuscany Region in Italy through the "Bando Unico Ricerca e Sviluppo anno 2012 del POR CReO". 


\section{References}

[1] K. Al-attab, Z. Zainal, Externally fired gas turbine technology: A review, Applied Energy 138 (0) (2015) $474-487$.

[2] M. Kautz, U. Hansen, The externally-fired gas-turbine (EFGT-Cycle) for decentralized use of biomass, Applied Energy 84 (78) (2007) 795 - 805.

[3] D. Cocco, P. Deiana, G. Cau, Performance evaluation of small size externally fired gas turbine (EFGT) power plants integrated with direct biomass dryers, Energy 31 (1011) (2006) 1459 - 1471.

[4] A. Datta, R. Ganguly, L. Sarkar, Energy and exergy analyses of an externally fired gas turbine (EFGT) cycle integrated with biomass gasifier for distributed power generation, Energy 35 (1) (2010) 341 - 350 .

[5] A. Pantaleo, S. Camporeale, N. Shah, Thermo-economic assessment of externally fired micro-gas turbine fired by natural gas and biomass: Applications in Italy, Energy Conversion and Management 75 (0) (2013) 202 213.

[6] S. Cordiner, V. Mulone, Experimental-numerical analysis of a biomass fueled microgeneration power-plant based on microturbine, Applied Thermal Engineering 71 (2) (2014) 905 - 912.

[7] S. Barsali, A. D. Marco, R. Giglioli, G. Ludovici, A. Possenti, Dynamic modelling of biomass power plant using micro gas turbine, Renewable Energy 80 (0) (2015) $806-818$.

[8] A. Traverso, A. F. Massardo, R. Scarpellini, Externally fired micro-gas turbine: Modelling and experimental performance, Applied Thermal Engineering 26 (16) (2006) 1935 - 1941.

[9] K. Al-attab, Z. Zainal, Performance of high-temperature heat exchangers in biomass fuel powered externally fired gas turbine systems, Renewable Energy 35 (5) (2010) $913-920$. 
[10] F. Baina, A. Malmquist, L. Alejo, B. Palm, T. H. Fransson, Analysis of a high-temperature heat exchanger for an externally-fired micro gas turbine, Applied Thermal Engineering 75 (2015) 410 - 420.

[11] F. Baina, A. Malmquist, L. Alejo, T. H. Fransson, Effect of the fuel type on the performance of an externally fired micro gas turbine cycle, Applied Thermal Engineering 87 (2015) 150 - 160.

[12] Q. Xiong, S.-C. Kong, A. Passalacqua, Development of a generalized numerical framework for simulating biomass fast pyrolysis in fluidized-bed reactors, Chemical Engineering Science 99 (2013) 305 - 313.

[13] Q. Xiong, S. Aramideh, S.-C. Kong, Modeling effects of operating conditions on biomass fast pyrolysis in bubbling fluidized bed reactors, Energy and Fuels 27 (10) (2013) 5948-5956.

[14] Q. Xiong, S. Aramideh, A. Passalacqua, S.-C. Kong, Biotc: An open-source cfd code for simulating biomass fast pyrolysis, Computer Physics Communications 185 (6) (2014) 1739-1746.

[15] E. Simsek, B. Brosch, S. Wirtz, V. Scherer, F. Krll, Numerical simulation of grate firing systems using a coupled cfd/discrete element method (dem), Powder Technology 193 (3) (2009) 266 - 273.

[16] A. Mahmoudi, M. Markovic, B. Peters, G. Brem, An experimental and numerical study of wood combustion in a fixed bed using euler-lagrange approach (XDEM), Fuel 150 (2015) 573-582.

[17] A. Anca-Couce, N. Zobel, H. Jakobsen, Multi-scale modeling of fixedbed thermo-chemical processes of biomass with the representative particle model: Application to pyrolysis, Fuel 103 (2013) 773-782.

[18] H. Strm, H. Thunman, A computationally efficient particle submodel for cfd-simulations of fixed-bed conversion, Applied Energy 112 (2013) 808817. 
[19] C. Yin, L. Rosendahl, S. Clausen, S. L. Hvid, Characterizing and modeling of an $88 \mathrm{MW}$ grate-fired boiler burning wheat straw: Experience and lessons, Energy 41 (1) (2012) 473 - 482.

[20] A. Parente, C. Galletti, J. Riccardi, M. Schiavetti, L. Tognotti, Experimental and numerical investigation of a micro-CHP flameless unit, Applied Energy 89 (1) (2012) 203-214.

[21] P. Leoni, M. Paci, N. Rossi, E. Tosi, S. Gasperetti, G. Coraggio, M. Faleni, Detailed long-term experimental characterization of a small- sized externally fired gas turbine power plant, European Biomass Conference and Exhibition (2015) IBO.8.4.

[22] C. Yin, L. A. Rosendahl, S. K. Kr, Grate-firing of biomass for heat and power production, Progress in Energy and Combustion Science 34 (6) (2008) $725-754$.

[23] J. A. Arthur, Reactions between carbon and oxygen, Trans Faraday Soc 47 (1951) 164-178.

[24] L. Tognotti, J. Longwell, A. Sarofim, The products of the high temperature oxidation of a single char particle in an electrodynamic balance, Symposium (International) on Combustion 23 (1) (1991) 1207 - 1213.

[25] C. Yin, L. Rosendahl, S. K. Kr, S. Clausen, S. L. Hvid, T. Hille, Mathematical modeling and experimental study of biomass combustion in a thermal 108 mw grate-fired boiler, Energy \& Fuels 22 (2) (2008) 1380-1390.

[26] M. Falcitelli, S. Pasini, N. Rossi, L. Tognotti, CFD+reactor network analysis: An integrated methodology for the modeling and optimisation of industrial systems for energy saving and pollution reduction, Applied Thermal Engineering 22 (8) (2002) 971-979.

[27] B. Launder, D. Spalding, The numerical computation of turbulent flows, Computer Methods in Applied Mechanics and Engineering 3 (2) (1974) 269 -289 . 
[28] T. H. Shih, W. W. Liou, A. Shabbir, Z. Yang, J. Zhu, New k-eeddy viscosity model for high Reynolds number turbulent flows model development and validation., Computers Fluids. 24 (3) (1995) 227-238.

[29] D. Wilcox, Re-assessment of the scale-determining equation for advanced turbulence models, AIAA Journal 26 (11) (1988) 1299-1310.

[30] B. F. Magnussen, B. H. Hjertager, On mathematical modeling of turbulent combustion with special emphasis on soot formation and combustion, Symposium International on Combustion 16 (1) (1977) 719-729.

[31] T. Smith, Z. Shen, J. Friedman, Evaluation of coefficients for the weighted sum of gray gases model, Journal of heat transfer 104 (4) (1982) 602-608.

[32] C. Yin, L. Rosendahl, S. Kr, S. Clausen, S. Hvid, T. Hiller, Mathematical modeling and experimental study of biomass combustion in a thermal 108 mw grate-fired boiler, Energy and Fuels 22 (2) (2008) 1380-1390.

[33] L. A. Rosendahl, C. Yin, S. K. Kr, K. Friborg, P. Overgaard, Physical characterization of biomass fuels prepared for suspension firing in utility boilers for CFD modelling, Biomass and Bioenergy 31 (5) (2007) 318 325.

[34] A. Shiehnejadhesar, R. Scharler, R. Mehrabian, I. Obernberger, Development and validation of cfd models for gas phase reactions in biomass grate furnaces considering gas streak formation above the packed bed, Fuel Processing Technology 139 (2015) $142-158$.

[35] S. K. Kr, Numerical modelling of a straw-fired grate boiler, Fuel 83 (9) (2004) 1183-1190.

[36] C. Galletti, G. Coraggio, L. Tognotti, Numerical investigation of oxynatural-gas combustion in a semi-industrial furnace: validation of CFD sub-models, Fuel 109 (2013) 445-460. 
[37] S. Zahirovi, R. Scharler, P. Kilpinen, I. Obernberger, Validation of flow simulation and gas combustion sub-models for the CFD-based prediction of NOx formation in biomass grate furnaces, Combustion Theory and Modelling 15 (1) (2011) 61-87. 


\section{List of Figures}

$1 \quad$ EFGT plant flow sheet. . . . . . . . . . . . . . . . . . 26

2 Sketch of the boiler, with indication of the measurement locations

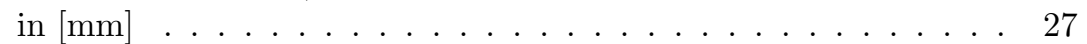

3 The Aspen Plus ${ }^{\circledR}$ model . . . . . . . . . . . . . . . . . . . . . . 28

4 Scheme of the three CFD models. . . . . . . . . . . . . . . . . . 29

5 Comparison between experimental (a) axial and (b) transversal profiles of temperature and those predicted by model \#1 (uniform release), model \#2 with experienced-based (zonal model) and optimized (zonal model-opt) conversion values, model \#3 (CFD

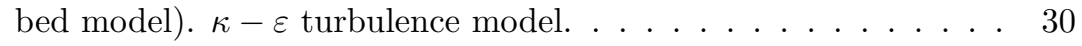

6 Comparison between experimental (a) axial and (b) transversal profiles of volumetric fraction of $\mathrm{O}_{2}$ and $\mathrm{CO}_{2}$ and those predicted by model \#1 (uniform release), model \#2 with experienced-based (zonal model) and optimized (zonal model-opt) conversion values,

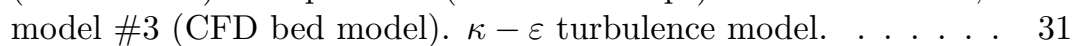

7 Vector plot, pathlines and temperature distribution in the case of model \#2. $\kappa-\varepsilon$ turbulence model. . . . . . . . . . . . . . . . 32

8 Vector plot, pathlines and temperature contours plot in the case of model \#3. $\kappa-\varepsilon$ turbulence model. . . . . . . . . . . . . . . . 33

9 Comparison between experimental (a) axial and (b) transversal profiles of temperature and those predicted by model \#3 (CFD bed model) using different turbulence models: standard $\kappa-\varepsilon$ (SKE), realizable $\kappa-\varepsilon(\mathrm{RKE})$ and standard $\kappa-\omega$ (SKW) model. 34

10 The porous media model above the grate of the boiler . . . . . . 35

11 Pathlines in the case of (a) CFD 3 model , (b) $1^{\text {st }}$ porous media model and (c) $3^{\text {st }}$ porous media model coloured by velocity

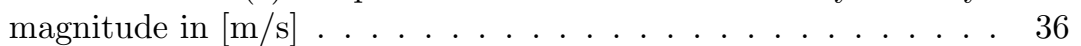




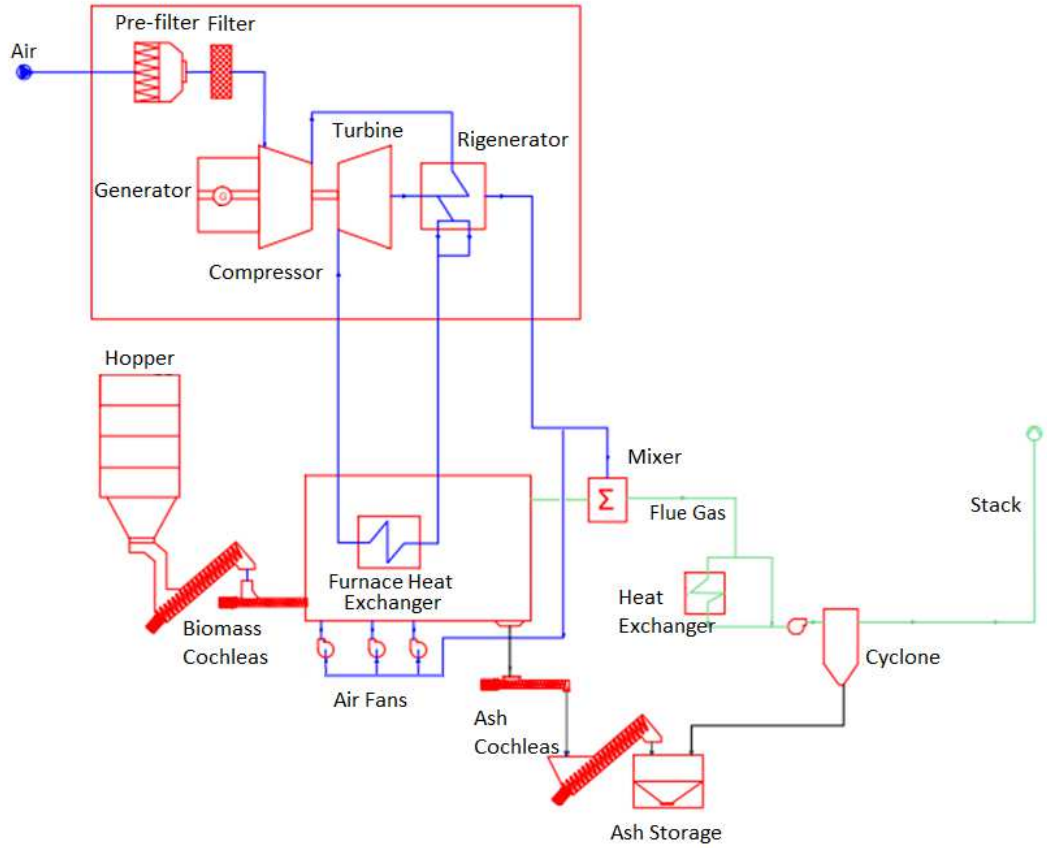

Figure 1: EFGT plant flow sheet. 

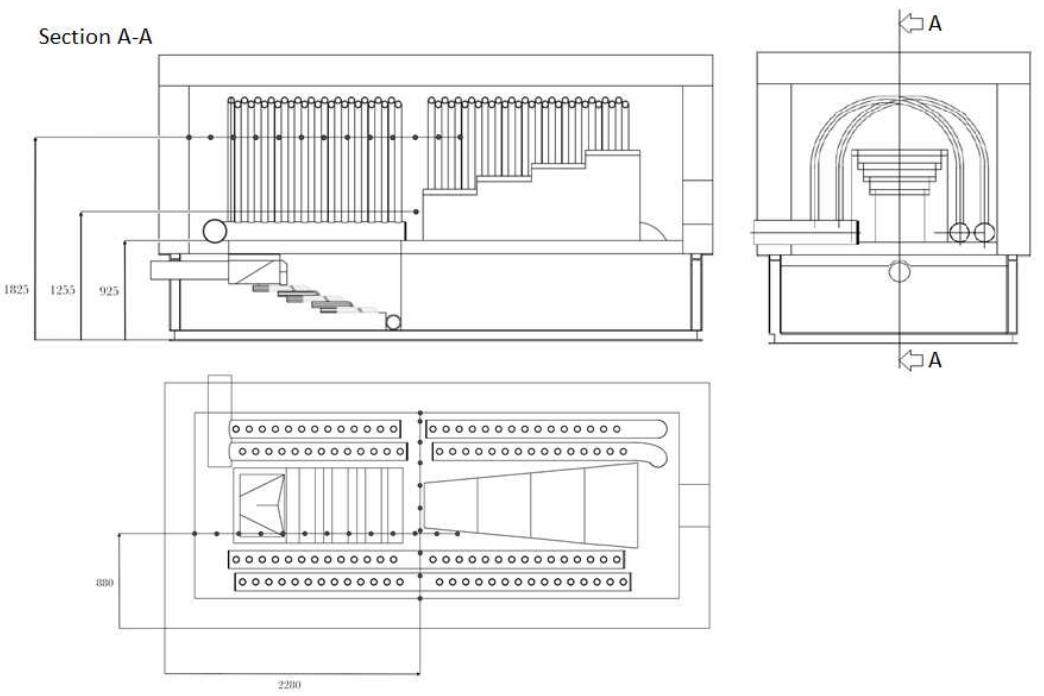

Figure 2: Sketch of the boiler, with indication of the measurement locations in [mm] 


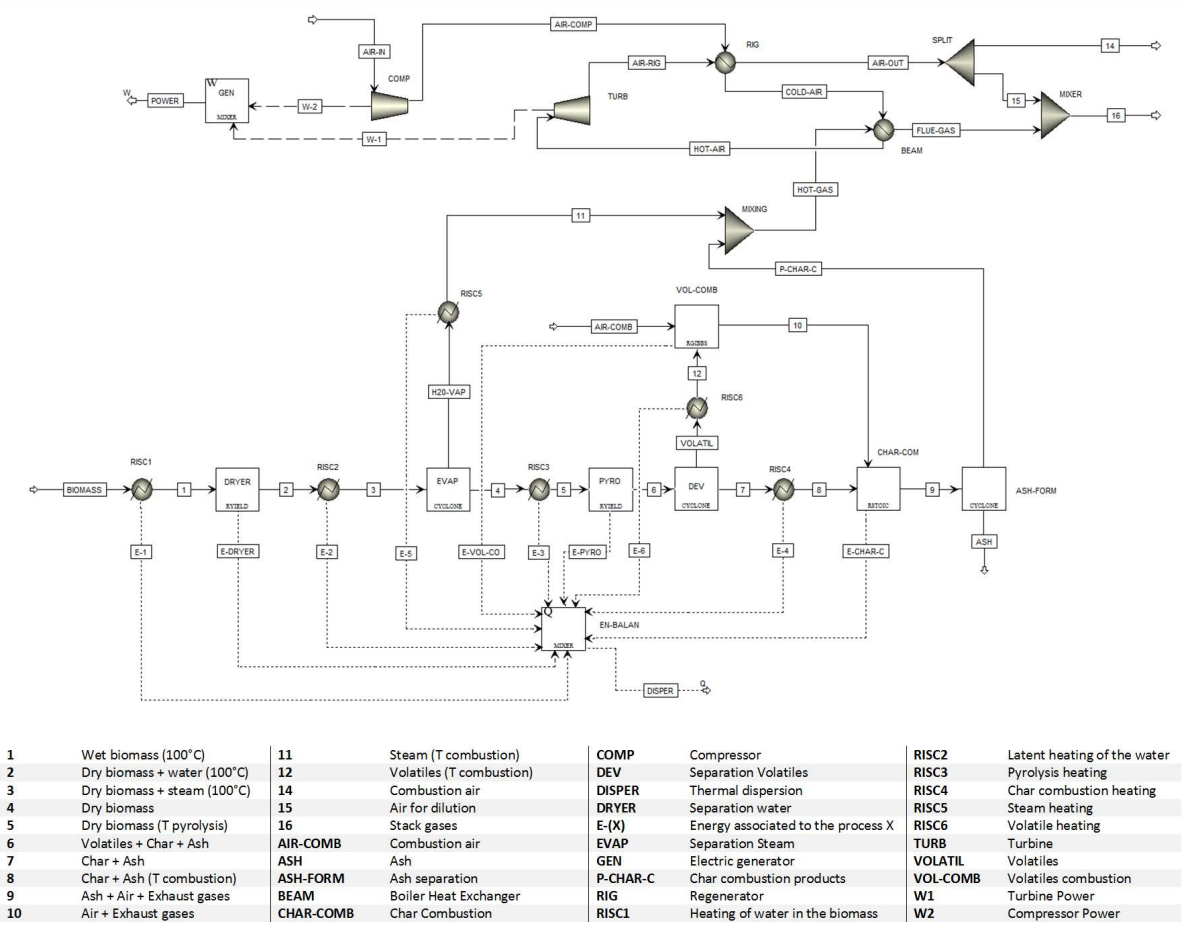

Figure 3: The Aspen Plus ${ }^{\circledR}$ model 

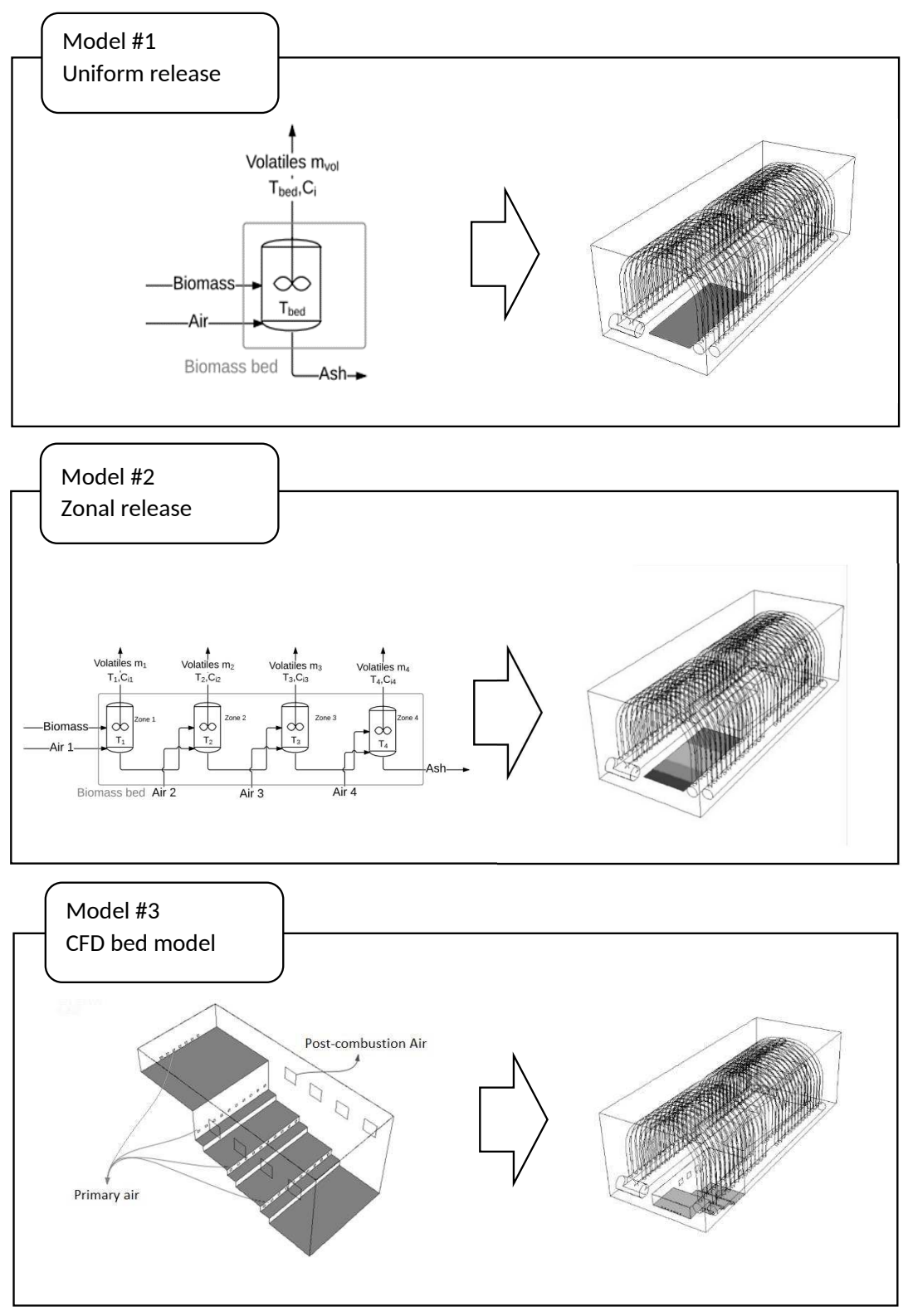

Figure 4: Scheme of the three CFD models. 

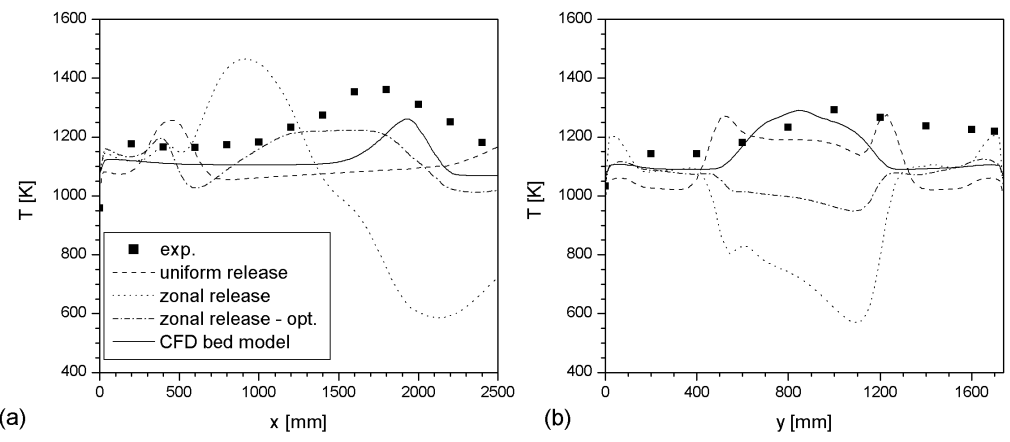

Figure 5: Comparison between experimental (a) axial and (b) transversal profiles of temperature and those predicted by model \#1 (uniform release), model \#2 with experiencedbased (zonal model) and optimized (zonal model-opt) conversion values, model \#3 (CFD bed model). $\kappa-\varepsilon$ turbulence model. 

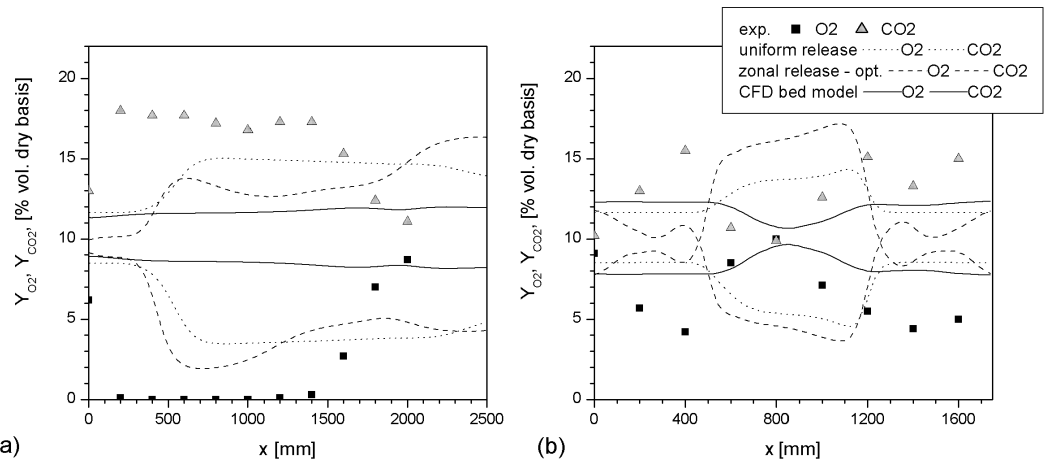

Figure 6: Comparison between experimental (a) axial and (b) transversal profiles of volumetric fraction of $\mathrm{O}_{2}$ and $\mathrm{CO}_{2}$ and those predicted by model \#1 (uniform release), model \#2 with experienced-based (zonal model) and optimized (zonal model-opt) conversion values, model \#3 (CFD bed model). $\kappa-\varepsilon$ turbulence model. 


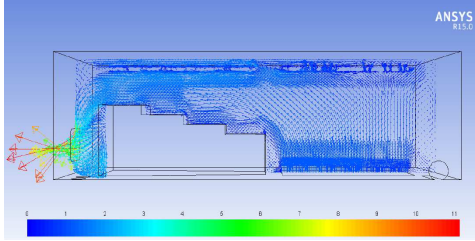

(a)

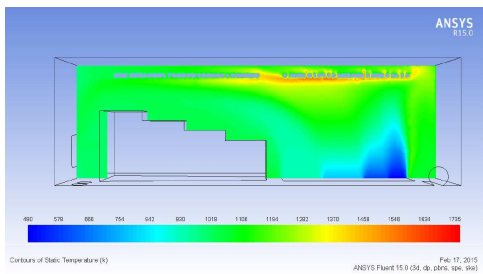

(c)

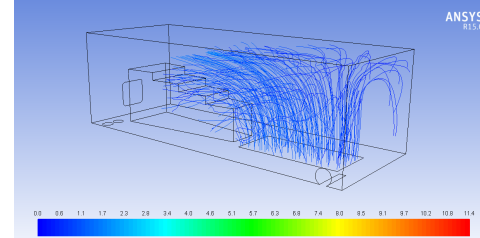

(b)

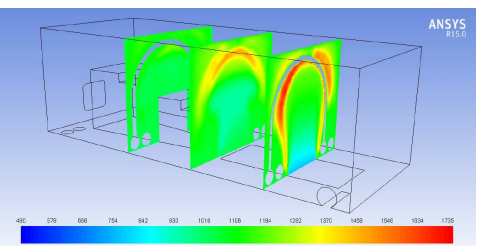

(d)

Figure 7: Vector plot, pathlines and temperature distribution in the case of model \#2. $\kappa-\varepsilon$ turbulence model. 


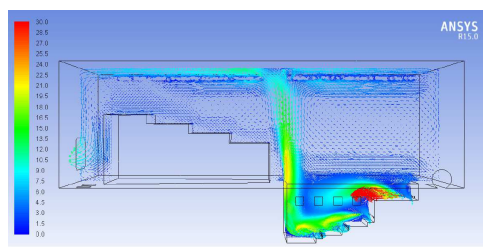

(a)

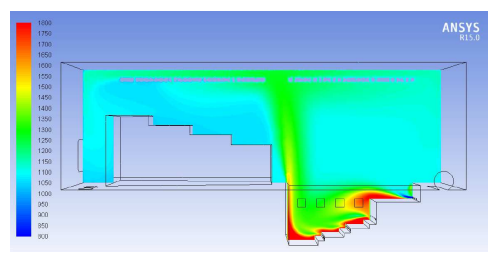

(c)

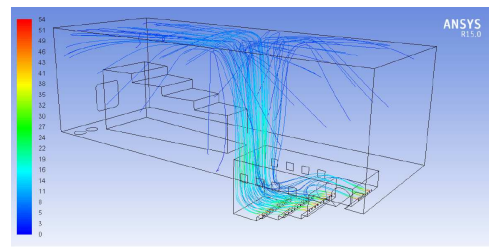

(b)

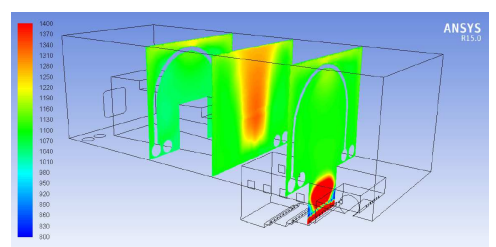

(d)

Figure 8: Vector plot, pathlines and temperature contours plot in the case of model \#3. $\kappa-\varepsilon$ turbulence model. 

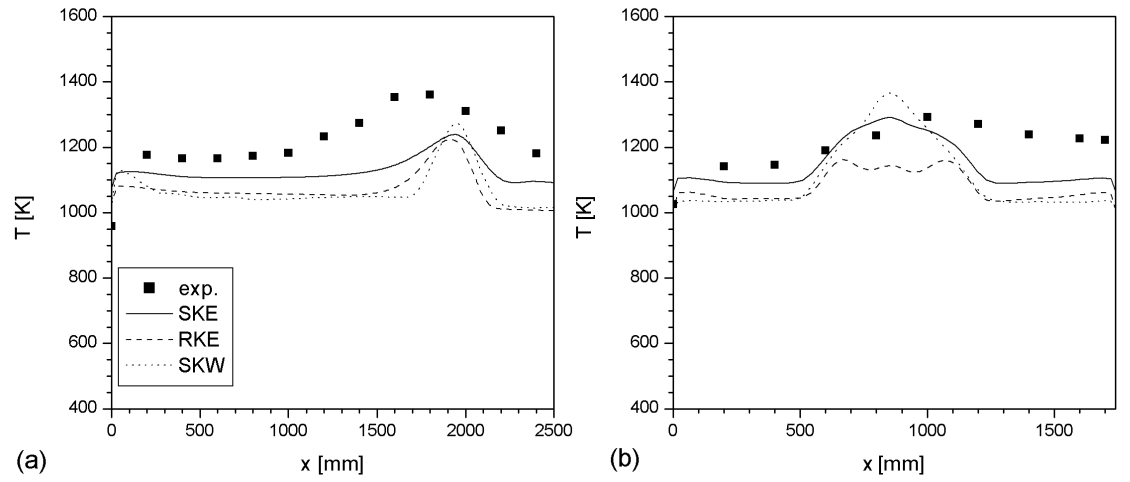

Figure 9: Comparison between experimental (a) axial and (b) transversal profiles of temperature and those predicted by model \#3 (CFD bed model) using different turbulence models: standard $\kappa-\varepsilon$ (SKE), realizable $\kappa-\varepsilon$ (RKE) and standard $\kappa-\omega$ (SKW) model. 


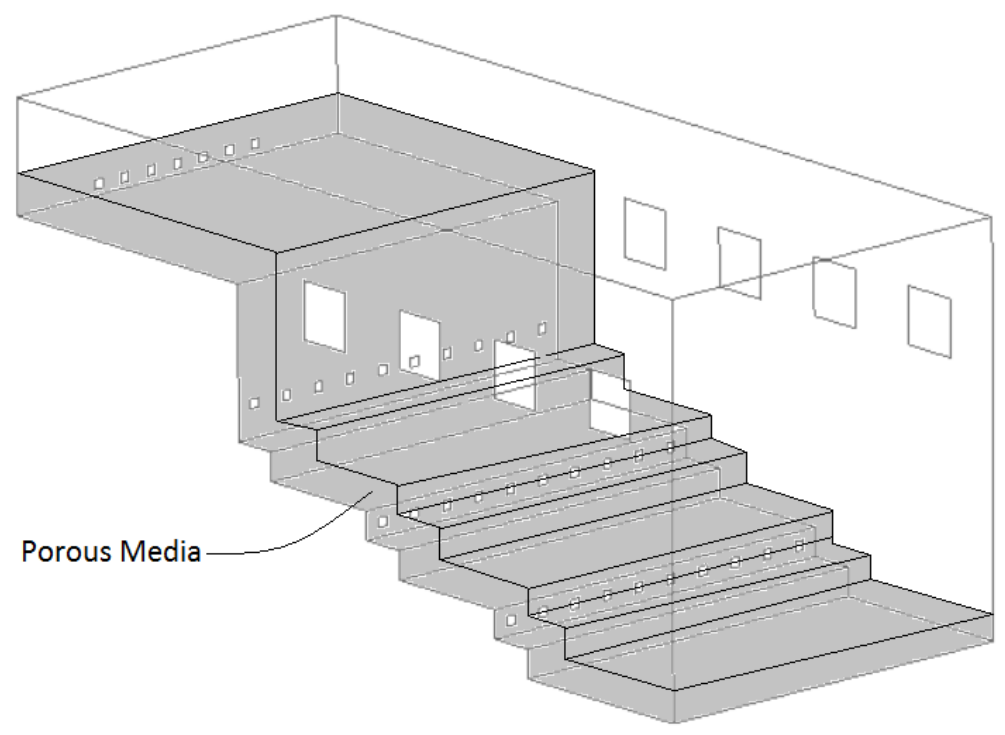

Figure 10: The porous media model above the grate of the boiler 


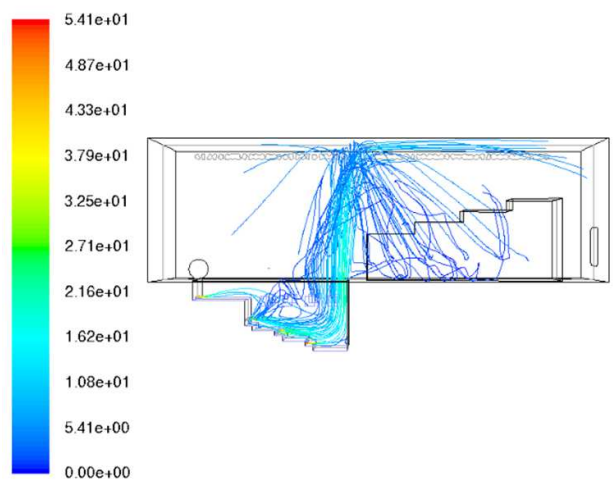

(a)

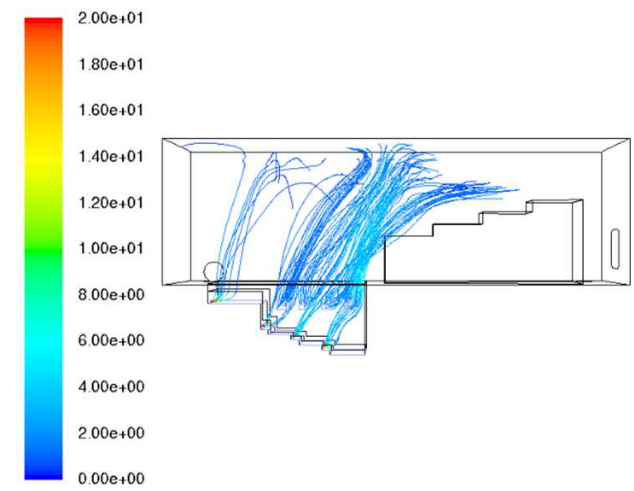

(b)

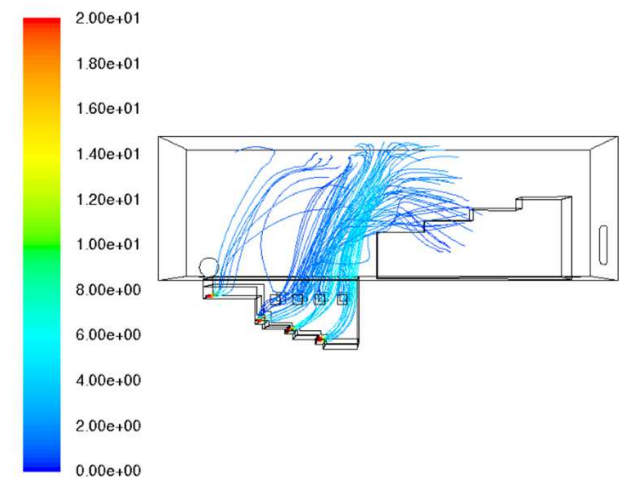

(c)

Figure 11: Pathlines in the case of (a) CFD 3 model , (b) $1^{\text {st }}$ porous media model and (c) $3^{\text {st }}$ porous media model coloured by velocity magnitude in $[\mathrm{m} / \mathrm{s}]$ 


\section{List of Tables}

$1 \quad$ Average operating conditions and proximate/ultimate analysis in

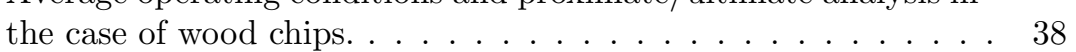

$2 \quad$ Results of the process simulation. . . . . . . . . . . . . . . 39

$3 \quad$ Extension (in percentage of the total grate length $L=1.6 \mathrm{~m}$ ) and conversion rate of each biomass combustion process for model \#2 as taken from the literature (experience-based) [25] and optimized for the present boiler (end-iteration) $\ldots \ldots \ldots \ldots$. . . . . . . 40

$4 \quad$ Average relative error on temperature and average absolute error on $\mathrm{CO}_{2}$ as evaluated for the different models along the axial and transversal directions. $\kappa-\varepsilon$ turbulence model. . . . . . . . . . . 41

5 Void fraction $\epsilon$, diameter $d$ and height $h$ of the cylindrical wood chips, equivalent diameter $d_{p}$ used for setting the porous region.$\quad 42$ 
Table 1: Average operating conditions and proximate/ultimate analysis in the case of wood chips.

\begin{tabular}{|c|c|c|c|c|c|}
\hline \multirow{2}{*}{\multicolumn{3}{|c|}{ BIOMASS }} & \multicolumn{3}{|l|}{ FLUE GAS } \\
\hline & & & $\mathrm{O}_{2}$ & $\%$ (dry) & 11.9 \\
\hline Carbon & \%wt (dry) & 52.1 & $\mathrm{CO}_{2}$ & $\%$ (dry) & 7.8 \\
\hline Hydrogen & \%wt (dry) & 6.2 & $C O$ & ppm (dry) & 45 \\
\hline Oxygen & \%wt (dry) & 40.68 & NO & ppm (dry) & 42 \\
\hline Nitrogen & $\%$ wt (dry) & 0.1 & $\mathrm{SO}_{2}$ & $\frac{m g}{N m^{3}}$ (dry) & 22 \\
\hline Sulphur & \%wt (dry) & 0.02 & Temperature & ${ }^{\circ} \mathrm{C}$ & 748 \\
\hline Moisture & \%wt (wet) & 21.9 & COMB. AIR & & \\
\hline $\begin{array}{l}\text { Ash } \\
\text { Fived Carbon }\end{array}$ & \%wt (wet) & $\begin{array}{l}0.9 \\
134\end{array}$ & Temperature & ${ }^{\circ} \mathrm{C}$ & 220 \\
\hline $\begin{array}{l}\text { Volatiles } \\
\text { ned }\end{array}$ & $\%$ wt (wet) & $\begin{array}{l}10.4 \\
64\end{array}$ & TUBES AIR & & \\
\hline Feeding Rate & $\mathrm{kg} / \mathrm{s}$ & 0.051 & Mass Flow Rate & $\mathrm{kg} / \mathrm{s}$ & 0.68 \\
\hline LHV & $\mathrm{MJ} / \mathrm{kg}$ & 15.52 & Inlet Temp. & ${ }^{\circ} \mathrm{C}$ & 470 \\
\hline & & & Outlet Temp. & ${ }^{\circ} \mathrm{C}$ & 791 \\
\hline
\end{tabular}


Table 2: Results of the process simulation.

\begin{tabular}{ccc}
\hline Parameter & Units & Value \\
\hline Combustion Air Mass Flow Rate & $\mathrm{kg} / \mathrm{s}$ & 0.527 \\
Flue Gas Mass Flow Rate & $\mathrm{kg} / \mathrm{s}$ & 0.575 \\
Furnace Heat Losses & $\mathrm{kW}$ & 90 \\
\hline
\end{tabular}


Table 3: Extension (in percentage of the total grate length $L=1.6 \mathrm{~m}$ ) and conversion rate of each biomass combustion process for model \#2 as taken from the literature (experience-based) 25 and optimized for the present boiler (end-iteration)

\begin{tabular}{cccc}
\hline \multicolumn{4}{c}{ Experience-based conversion rate } \\
\hline Distance [\%] & Evaporation [\%] & Devolatilization [\%] & Char oxidation [\%] \\
14.6 & 85 & 15 & 5 \\
20 & 15 & 85 & 35 \\
33.1 & 0 & 0 & 55 \\
32.3 & 0 & 0 & 5 \\
\hline \multicolumn{4}{c}{ End-iteration conversion rate } \\
\hline Distance [\%] & Evaporation [\%] & Devolatilization [\%] & Char oxidation [\%] \\
14.6 & 85 & 20 & 5 \\
20 & 15 & 40 & 10 \\
33.1 & 0 & 40 & 35 \\
32.3 & 0 & 0 & 50 \\
\hline
\end{tabular}


Table 4: Average relative error on temperature and average absolute error on $\mathrm{CO}_{2}$ as evaluated for the different models along the axial and transversal directions. $\kappa-\varepsilon$ turbulence model.

\begin{tabular}{ccc}
\hline \multicolumn{3}{c}{ Axial profile } \\
\hline Model & Temperature $E_{r} \%$ & $\mathrm{CO}_{2} E_{a}$ \\
model \#1 & 12.13 & 8.18 \\
model \#2 & 10.35 & 8.20 \\
model \#3 & 8.18 & 5.04 \\
model \#4 & 10.03 & 5.25 \\
\hline \multicolumn{3}{c}{ Transversal profile } \\
\hline Model & Temperature $E_{r} \%$ & $\mathrm{CO}_{2} E_{a}$ \\
model \#1 & 8.91 & 5.80 \\
model \#2 & 10.92 & 5.89 \\
model \#3 & 6.43 & 5.59 \\
model \#4 & 9.09 & 4.75 \\
\hline
\end{tabular}


Table 5: Void fraction $\epsilon$, diameter $d$ and height $h$ of the cylindrical wood chips, equivalent diameter $d_{p}$ used for setting the porous region

\begin{tabular}{ccccc}
\hline & $\epsilon[-]$ & $d[\mathrm{~mm}]$ & $h[\mathrm{~mm}]$ & $d_{p}[\mathrm{~mm}]$ \\
\hline $1^{\text {st }}$ porous media & 0.51 & 6 & 10 & 13 \\
$2^{\text {nd }}$ porous media & 0.51 & 15 & 35 & 32 \\
$3^{\text {rd }}$ porous media & 0.51 & 25 & 30 & 48 \\
\hline
\end{tabular}

